\title{
Research Status and Trend Analysis on Context-Aware Application (2005-2014)
}

\author{
Liyi Zhang ${ }^{1,2}$ and Cong Yin ${ }^{1 *}$ \\ ${ }^{1}$ School of Information Management, Wuhan University, Wuhan, China \\ ${ }^{2}$ Center for the Study of Information Resources, Wuhan University, Wuhan, China \\ ${ }^{1}$ Liyizhang@whu.edu.cn, ${ }^{2}$ simusic@whu.edu.cn
}

\begin{abstract}
Recently, context-aware application has been one of the hottest researching fields in the domain of business intelligence. By reviewing the progress of contex-aware application in these years, this paper proposes a four-layer classification framework and gives an analysis and comparison to the concept and theory, context aware computing and typical application which are related to context-aware applicafion. It also summarizes their characteristics and effects from the point of practical pse. Lastly, some discussions and suggestions were given to emphasize the difficultiv of current application conditions.
\end{abstract}

Keywords: Context-aware; Context modelling; User preference elicitation; Context-aware application; User interface

\section{Introduction}

With the development of mobile communication network, cloud computing and artificial intelligence and the appearante and popularization of wearable device as well as the price of sensor are fallng, smart life is on the road in our daily life. To provide adequate service for the users, applications and services should be aware of their contexts and automaticallyadapt to theil changing contexts, which is known as context-awareness $[1,2]$. Schilit and Theimer first introduced the term "context", describing it as location, identities of nearby people, objects and changes to those objects [3]. Hull et al. described context as the aspects of the current situation [4]. However, these definitions are too broad. Definition given by Dey and Abowd is widely recognized [5]. According to their definition, contex refers to

"Any information that can be used to characterize the situation of entities (i.e., whether a person, place or object) that are considered releyant to the interaction between a user and an application, including the user and the application themselves."

the traditional recommendation system, people always pay attention to the relation
between users and items, ignoring the context information between them. In order to
improve the accuracy of recommendation and the satisfaction of users, some experts
introduce context-aware computing theory into the recommended system. Numerous
journals and conferences articles related to context-aware application have been
published. Many researchers especially universities and institutes such as Free University
of Bozen-Bolzano [6], Technical University of Munich [7], Seoul National University [8],
Microsoft Research [9] are interested in context-aware application. ACM Conference on
Recommender Systems (RecSys) has holding Workshops on Context-Aware
Recommender Systems (CARS) from 2009, which mainly involved in the present
hotspots and critical issues, such as context data acquisition and context modeling. 
Hong et al proposed a five-level integrated framework for context-aware system: concept and research layer, network layer, middleware layer, application layer and user infrastructure layer, which is particularly instructive for the later research [10]. This architecture also can be applied to context-aware application. However, it has some defects the internal subdivisions of the application layer are unreasonable; the review only collects journals but ignores the academic value of the other literature; the review covers the period from 2000 to 2007, but in recent five years, research on context-aware application has been changing every day. Therefore, it is necessary for a review analysis again. In brief, the main objectives of this review are:

(1) To classify and summarize research relevant for context-aware application.

(2) Provide a conceptual framework for the integration and classification of articles.

(3) Give suggestions for other researchers by the literature review.

The study is organized as follows: firstly, the research methods used in the data collection are described; secondly, the criteria used for classifying the literature on context-aware application is presented; thirdly, the context-aware application artictes are analyzed and the classification results are reported; finally, conclusions are presented and the future research trend is discussed.

\section{Research Methodology}

\subsection{Data Collection and Processing}

Considering most of the contemporary research is published in conference proceedings, we included both academic journals from various disciplines and conference proceedings in our search. Despite a potentially lover quality of the conference proceedings, they are informative for charting the current research topics in this rapidly progressing area of research, and for identifying gâps o be covered by future research. We also expect that the best conference papers will evolve to journal articles and thus serve as leading indicators for the focus of future journal publications.

We set three selection Criteria for extracting context-aware articles. If the papers did not meet the criteria, then they were excluded. The criteria are described as follows:

(1) We started the literature search with a wide systematic scan of online academic journals and conference databases based on the keywords "context-aware". The following databases were searched: ProQuest Direct, EBSCO Business Source Premier, Science Direct, Spring Link Onl ne Libraries, IEEE Xplore and ACM Digital Library.

(2) This paper manny surveys the articles published from 2005 to 2014, perhaps involved a small amount of literatures before 2004.Meanwhile,some papers which were irrelevant to context-aware (except paper titles) or too pale in content to be useful were eliminated.

(3) To ensure the quality of the conference papers, we focused our search on a few established conferences that are listed in Table 1. Besides, some other high-quality literatures from other conference also have been collected. 
Table 1. Main Conferences Included in the Literature Search

\begin{tabular}{|l|}
\hline Conferences by topics \\
\hline Computing \& Processing (Hardware/Software) \\
\hline International Conference On Pervasive Computing And Applications(ICPCA) \\
\hline Asia-Pacific Services Computing Conference(APSCC) \\
\hline International Conference on Ubi-Media Computing (U-Media) \\
\hline International Conference on Embedded and Ubiquitous Computing(EUC) \\
\hline Communication, Networking \& Broadcasting \\
\hline International Conference On Advanced Communication Technology(ICACT) \\
\hline International Conference on Future Computer and Communication(ICFCC) \\
\hline International Wireless Communications and Mobile Computing Conference \\
\hline Signal Processing \& Analysis \\
\hline International Conference on Multimedia and Ubiquitous Engineering(ICMUE) \\
\hline International Symposium on Information Science and Engineering(ISISE) \\
\hline International Conference on Internet and Web Applications and Services(ICIW) \\
\hline Others \\
\hline Symposium on Usable privacy and security \\
\hline
\end{tabular}

The papers were selected according to the procedures shown in Figure 1. First of all, the articles were searched using six online databases. The total number of articles is 1492and the detailed information is as follows: REE Xplore (537), Springer Link Online Libraries (303), Science Direct (217). ACM Digital Library (235), ProQuest Direct (141) and EBSCO Business Source Premier (59). Next, 894 articles were excluded because they did not have the keyword "context-aware in the titles or abstracts. Finally, the articles were carefully reviewed toselect those that considered context-aware as the core part. 306 articles remained becaluse 292 articles did not meet the selection criteria. Based on these procedures, a total of 306 articles met all the selection criteria.

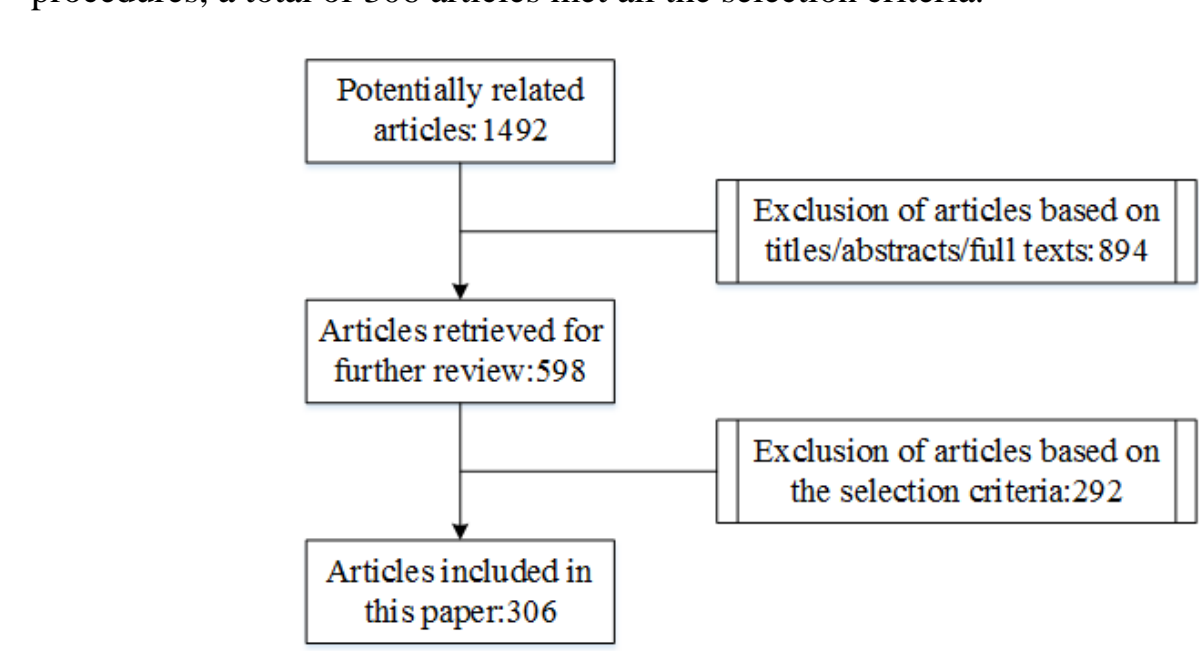

Figure 1. The Procedures to Select the Articles 


\subsection{Classification of Context-Aware Application Literature}

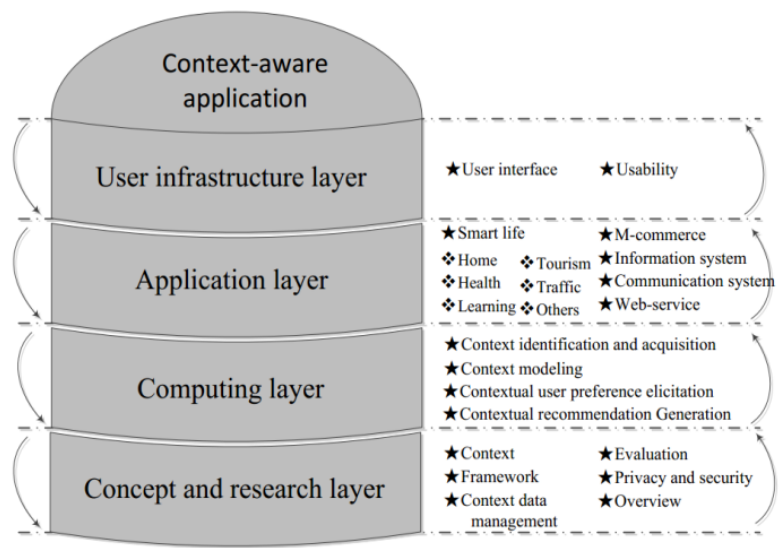

Figure 2. Classification Framework for Context-aware Application Papers

The classification framework is developed for classifying the literatures related with context-aware applications, which based on the literature that explores the context-aware prototype, systems, and application to offer classification criteria for dividing the literature appropriately. Hong et al. proposed a five-leyel integrated framework (concept and research layer, network layer, middleware layer, application layer and user infrastructure layer) for context-aware application [10]. In fact, the function of network layer and middleware layer can be combined for context-aware computing. In addition, the classification of context-aware applieation is defe tive: the application of smart space is too narrow that should be extended to tourism, traffic and others. Hence, the five-level framework proposed by Hong e al can also be reduced to a four-level framework: concept and research layer compung layer application layer and user infrastructure layer. The classification framewok for context-aware application is shown in Figure 2 the classification framework ecognizes that context-aware application articles consist of four levels and each of thennis discussed as follows:

2.2.1 Concept and Research Layer: It is the lowest level of the framework, which involves theories and foundation to construct context-aware systems. The articles included here describe the concept of context; the framework of context-aware system which illustrates acquiring, discovering, interpreting and accessing various contexts to build context-aware services; context data management; the evaluation that is focused on the evaluation method of the system and privacy and security when using context-aware application. Articles dealing with a general definition, foundational concepts of context-aware-application and so forth were grouped under the heading "context-aware overview, content and characteristics".

2.2.2 Computing Layer: Context-aware computing plays an important role in the comext-aware application, which mainly involves with the following technologies: 


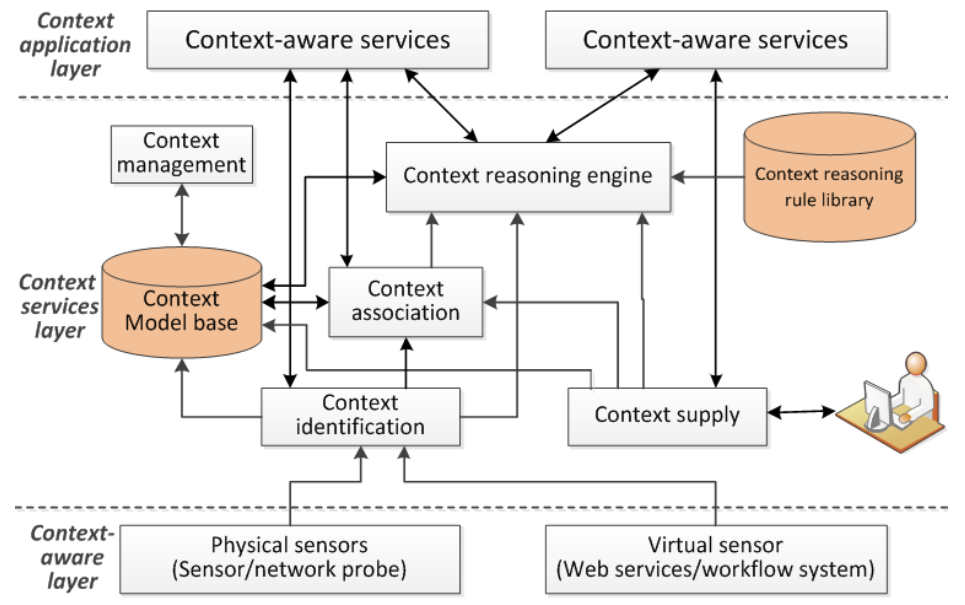

Figure 3. Technical Architecture of Context Identification and Acquisition

(1) Context identification and acquisition technology: The identification and acquisition of context not only provided by man-machine interaction, but it also recognized automatically by sensors [11]. In the man-machine interaction, the system will guide the users to express their current context accurately and input thenf into the system, to elicit the current context information of the users. While in the process of recognizing context automatically, direct context is commonly acquired by sensors or application software, whereas indirect context is obtained by inferring f12]. As Figure 3 depicts, context identification and acquisition te hnology architecture are built by different technologies to acquire the context effectively and interact with other applications.

(2) Context modeling technology: In context modeling, context information is integrated into the recommendation, and suitable algofitinns and models are designed to manage multidimensional contextual user preference. Although it is complex to process high-dimensional data for context modeling, it is also highly efficient to dig the correlation among the users, contexts and items. Context modeling approaches can be divided into two categovies: heuristro-based approaches and model-based approaches. The former such as the Nearest Neighbor algorithm [11], Cluster [13] are intuitive. However, papers on the similarity calcylation formula of context related high-dimensional data are still rare. Scholars should strengthen the research in this respect. The later such as Bayesian network [12]. Bayesian preference model [14], SVM [15] and tensor decomposition [16] used the method of machine learning to build the models. Compared with the former, model-based approaches are more time-consuming and great deals of parameters are needed for optimizing. Nevertheless, the later just requires a model, the data needed of which is much less than the original. So the data sparsity is reduced to some extent and the performance accuracy is raised as well [17].

(3) Contextual user preference elicitation technology: Preference is used to describe the ordering relation of two or more items for decision-makers. These technologies including two research ideas: quantitative analysis and qualitative analysis, and the main advantages and disadvantages between them are showed in Table 2 . 
Table 2. Comparison of Different Contextual user Preference Elicitation Approaches

\begin{tabular}{|c|c|c|}
\hline & The main advantages and disadvantages & Technology \\
\hline 惫 & $\begin{array}{l}\text { (1) Easy to quantize and calculate, and convenient for the } \\
\text { generation of recommendation and Top-n recommendation; } \\
\text { (2) Makes the preferences of each specific context user } \\
\text { form a total order, weak order expression between } \\
\text { preferences is not allowed, which is not good for describing } \\
\text { the relation between the preferences of any two specific } \\
\text { context users and logical reasoning. }\end{array}$ & $\begin{array}{l}\text { Collaborative } \\
\text { filtering; } \\
\text { Similarity } \\
\text { computation; } \\
\text { Cluster; } \\
\text { Decision } \\
\text { tree; }\end{array}$ \\
\hline 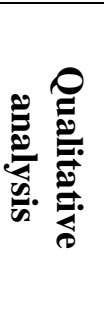 & $\begin{array}{l}\text { (1) It is good for describing the context users' preferences } \\
\text { which don't always satisfy the total order, and convenient } \\
\text { for handling the weak order of preferences (visualized, } \\
\text { natural), and can express the relation of the specific } \\
\text { examples of preferences of any two context users and carry } \\
\text { out logistical reasoning;(2) Not easy to quantize and } \\
\text { calculate. }\end{array}$ & $\begin{array}{l}\text { E-R diagram; } \\
\text { Strict partial } \\
\text { orden model; } \\
\text { Greedy } \\
\text { algorithm }\end{array}$ \\
\hline
\end{tabular}

(4) Contextual recommendation generation technology: This technology is used to generate recommendation according to the existing preferences of context users and by combining with the current contexts. In the traditional recommendation system, similar users have the similar preferences, ând Bora thinks that the preference of other like-minded users in similar context which towards an itêm in the current context should also be considered [18]. However, contextual recommendation generation technology is still facing many problems, such as which model to choose and how to optimize parameters, how to detect and resolve the Confliction of generation results based on multi-sources data fusion and so on.

2.2.3 Application Laver: With their serious computational power, the context-aware applications have an expansive prospect, which provide personalized services under the intelligent condifions (home, hospital, tourism, etc.) for the users. Baek et al designed a smart home care system based on the context-awareness technology. When a user wants to go to unfamiliar places to travel, it plays an important role as a tour guide [19]. Bellotti et al put forward implementing tour guides that present tourists with high-quality multimedia information and services [20]. More importantly, they could assist the users in the real-time event, and during the in-car trip as well. Based on a two-layer clustering analysis on the characteristics of music, Su et al designed an uMender system that divide users into different groups and generate recommendation according to the similarities of contexts [12]. Context-aware application can also be used in some other fields, such as M-commerce, information system and Communication system. Applications and services not only handle current task, situation and action but also, anticipate future behavior, moving point and problem of user which may be found in in our smart life.

2.2.4 User Infrastructure Layer: Mobility is the core of the context-awareness. It is characteristic for handheld devices and their users that they are continuously moving in several simultaneous fuzzy contexts [21]. Handheld device is limited by such factors as the inconveniences of keyboard input and smaller screens weaken, increase the load of human-computer interaction [22]. Therefore, research of user interface (UI) and usability of handheld device are of extremely important and urgent. 
In UI research, it is generally acknowledged that the contents are confusing when a screen changed due to a location change. To overcome inherent weaknesses of small interface such as phones and pads, research on user modeling and human-computer interaction for considering the emergence of ubiquitous and mobile computing environments should be strengthened. Usability involves investigating the user needs based on user interviews, field evaluations with users, and expert evaluations of context-aware services. When it comes to usability evaluation for context-aware application, some researchers suggested a hybrid evaluation method comprised of cognitive walkthrough and heuristic evaluation for UI supporting mobility of context-aware systems.

\section{Results of the Analysis}

According to the data collection selection criteria aforementioned, a total of 306 papers were reviewed ultimately, namely 197 journal papers, 91 conference papers, 14 master's and doctoral dissertations and 4 books. These papers are classified according to different criteria, and the basic characteristics are as follows :

\subsection{Distribution of Literatures by Online Database}

The article by online database is categorized in Table 3. There are atotal of 306 articles from online databases. In Table 3, IEEE Xplore is the highest proportion (101 articles, $33.01 \%$ ), because it offers articles of many journals (IEEE Pervasive Computing, IEEE Internet Computing and IEEE Wireless Comnunications) vhich have subject relevant to context-aware systems. Spring Link Onlin Libraries (61 articles, 19.93\%) have roughly the same proportion as Science Direct (58 articles, 18.95). Other online databases are ACM Digital Library (42 papers, 13.73\%), ProQuest Direct (21 papers, 6.86\%), Wiley InterScience (13 papers, 4.25\%) and EBSCO Business Source Premier (10 papers, $3.27 \%)$.

Table3. Distribution of Literatures by Online Database

\begin{tabular}{|l|c|c|}
\hline Online database & Articles & Proportion (\%) \\
\hline IEEEXplore & 101 & $33.01 \%$ \\
\hline Spring Link Online Libraries & 61 & $19.93 \%$ \\
\hline Science Direct & 58 & $18.95 \%$ \\
\hline ACM Dightat Library & 42 & $13.73 \%$ \\
\hline Proquest Direct & 21 & $6.86 \%$ \\
\hline Wilex InterScience Source & 13 & $4.25 \%$ \\
\hline $\begin{array}{l}\text { EBSCO Business } \\
\text { Premier }\end{array}$ & $\mathbf{3 0 6}$ & $\mathbf{1 0 0 \%}$ \\
\hline Total & & \\
\hline
\end{tabular}

\subsection{Distribution of Literatures by Year}

The number of articles by publication year is depicted in Figure 4. Numerous context-aware articles have grown considerably since 2005. From the figure, we can see that the number of articles in 2013 has becomes 7 times more than the number of articles in 2005. It is absolute that the concern about context-aware systems was increased and will be continued. Seen from the literatures, the number of journal and conference articles tends to be increasing as a whole, whereas the number of master's and doctoral dissertations and books is relatively small, and the details are as follows. 


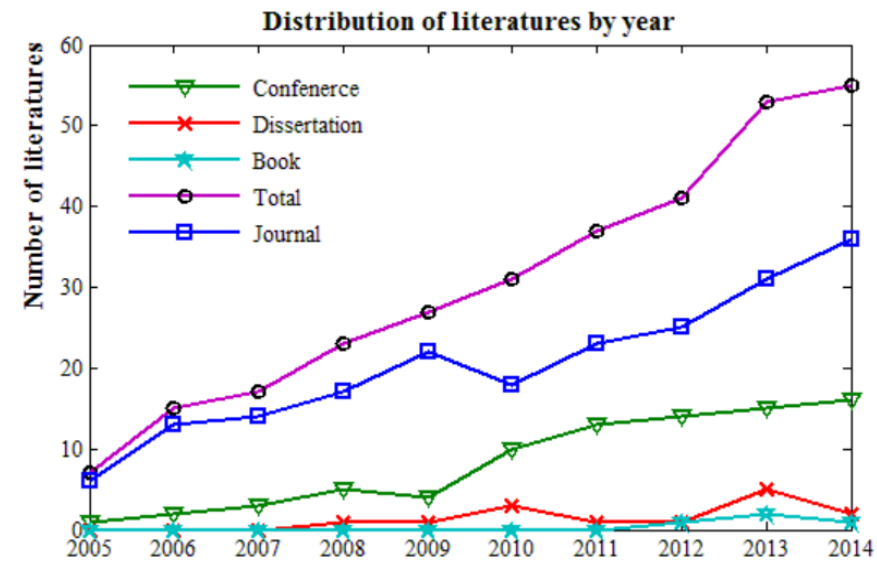

Figure 4. Distribution of Literatures by Year

\subsection{Distribution of Literatures by Literature Type}

The articles by journal literature type are categorized in Table 3. Journal papers is the highest proportion (197 articles, 64.38\%), other literatures are conferencé papers (91 articles, 29.74\%), Dissertations (14 thesis, 4.57\%) and books (4 books. 131\%).

\section{Table 4. Distribution of Literatures by Literature Type}

\begin{tabular}{|l|c|c|}
\hline Literature type & Articles & Proportion (\%) \\
\hline Journal papers & 205 & $66.99 \%$ \\
\hline Conference papers & 83 & $27.12 \%$ \\
\hline Dissertations & 14 & $4.58 \%$ \\
\hline Books & 4 & $1.31 \%$ \\
\hline Total & $\mathbf{3 0 6}$ & $\mathbf{1 0 0 \%}$ \\
\hline
\end{tabular}

3.3.1 Journal Papers. Table 5 lists the journals that had published three or more context-aware articles Expert Systems with Applications had by far the most articles (15 articles, 7.61\% IEEE Perrasive Computing published 10 articles (7.11\%). Int. J. of Mobile Comm mications had the third largest percentages (7articles, 3.55\%). Expert systems with applications is a refereed international journal whose focus is on exchanging information relating to expert and intelligent systems applied in industry, government, and universities worldwide. IEEE Pervasive Computing explores the many facets of pervasive and ubiquitous computing with research papers, departments covering wearable and mobile technologies, and more.

Tabre 5. Journals with Three or more Papers on Context-Aware Application
\begin{tabular}{|l|c|c|}
\hline Journal & Articles & Proportion of TJP* \\
\hline Expert Systems with Applications & 15 & $7.61 \%$ \\
\hline IEEE Pervasive Computing & 14 & $7.11 \%$ \\
\hline Int. J. of Mobile Communications & 7 & $3.55 \%$ \\
\hline Personal and Ubiquitous Computing & 6 & $3.19 \%$ \\
\hline Pervasive and Mobile Computing & 6 & $3.19 \%$ \\
\hline Wireless Personal Communications & 6 & $3.19 \%$ \\
\hline IEEE Intelligent Systems & 4 & $2.13 \%$ \\
\hline IEEE Communications Magazine & 3 & $1.60 \%$ \\
\hline *TJP represents Total of Journal Paper. & &
\end{tabular}


3.3.2 Conference Papers: Table 6 lists the conferences that had published three or more context-aware articles. ICACT had by far the most articles (9 articles, 9.89\%). ACM conference on Recommender systems had the second largest percentages of context-aware articles among the international conferences. International Conference on Advanced Communication Technology (ICACT) is an open forum for scholars, researchers, and engineers to the extensive exchange of information on newly emerging technologies, standards, services, and applications in the area of the advanced communications technology. ACM conference on Recommender systems is the premier international forum for the presentation of new research results, systems and techniques in the broad field of recommender systems.

Table 6. Conference with Three or more Papers on Context-Aware Application

\begin{tabular}{|l|c|c|}
\hline Conference & Articles & $\begin{array}{c}\text { Proportion } \\
\text { of TCP\% }\end{array}$ \\
\hline $\begin{array}{l}\text { International Conference on Advanced Communication } \\
\text { Technology, ICACT }\end{array}$ & 9 & $9.89 \%$ \\
\hline ACM conference on Recommender systems & 4 & $4.40 \%$ \\
\hline $\begin{array}{l}\text { International ACM SIGIR conference on Research and } \\
\text { development in information retrieval }\end{array}$ & 3 & $3.30 \%$ \\
\hline International conference on intelligent user interfaces & 3 & $3.30 \%$ \\
\hline $\begin{array}{l}\text { International Conference on Mobile,Ubiquitous } \\
\text { Computing, Systems, Services and Technologies }\end{array}$ & 3 & $3.30 \%$ \\
\hline $\begin{array}{l}\text { International Conference on Mobile Data } \\
\text { Management, }\end{array}$ & 3 & $3.30 \%$ \\
\hline Workshop on Context-Aware Movie Recommendation & 3 & $3.30 \%$ \\
\hline
\end{tabular}

*TCP represents Total of Conference Paper

3.3.3 Dissertations, and Books: According to the dissertations and books related to context-aware application, which many cover aspects such as the context-aware theory, framework[23], ata management 24], computing [25-29], privacy and security[30,31], application 32,33 ]. Not only, are the content of these dissertations and books high systematization and intricate, but also found out many unique theoretical viewpoints in the field of context-20yare application, which must be an important driving force for the context-aware application development.

\subsection{Distribution of Literatures by Subject}

Table 7 hows the distribution of articles by subject. Most papers (96articles, 31.37\%) were related to the concept and research layer. The application layer (95articles, 31.05\%) and the computing layer (93articles, 31.6\%) had the second and third largest percentages of context-aware application papers. User infrastructure layer had the lowest percentages, which is merely $7.19 \%$ of the total.

Overall, four major topics made up a large proportion within all reviewed papers. They were "Smart life"(53 papers),"Context modeling”(29 papers),"Contextual user preference elicitation"(27 papers) and "Context"(26 papers).All of these indicate that research on context-aware application is shifting from the basic research such as the concept of context-aware into the technologies as context modeling and user preference elicitation, which are the key to the applications implementation. 
Table 7. Distribution of Literatures by Subject

\begin{tabular}{|c|c|c|c|}
\hline Classification criteria & Articles & $\begin{array}{c}\text { Percentage } \\
\text { of subject }\end{array}$ & $\begin{array}{c}\text { Percentage of } \\
\text { all subjects }\end{array}$ \\
\hline 1 Concept and research layer & 96 & $100 \%$ & $31.37 \%$ \\
\hline 1.1 Context & 26 & $27.08 \%$ & $8.49 \%$ \\
\hline 1.2 Framework & 20 & $20.83 \%$ & $6.54 \%$ \\
\hline 1.3 Context data management & 16 & $16.67 \%$ & $5.23 \%$ \\
\hline 1.4 Evaluation & 10 & $10.42 \%$ & $3.27 \%$ \\
\hline 1.5 Privacy and security & 15 & $15.63 \%$ & $4.90 \%$ \\
\hline 1.6 Overview & 9 & $9.37 \%$ & $2.94 \%$ \\
\hline 2 Computing layer & 93 & $100 \%$ & $30.39 \%$ \\
\hline 2.1 Context identification and acquisition & 15 & $16.13 \%$ & $4.90 \%$ \\
\hline 2.2 Context modeling & 29 & $31.18 \%$ & $9.48 \%$ \\
\hline 2.3 Contextual user preference elicitation & 27 & $29.03 \%$ & $8.82 \%$ \\
\hline $\begin{array}{l}2.4 \text { Contextual recommendation } \\
\text { generation }\end{array}$ & 22 & $23.66 \%$ & \\
\hline 3 Application layer & 95 & $100 \%$ & $31.05 \%$ \\
\hline 3.1 Smart life & 53 & $55.79 \%$ & $17.32 \%$ \\
\hline 3.1.1 Home & 12 & $12.63 \%$ & $3.92 \%$ \\
\hline 3.1.2 Health & 13 & $13.68 \%$ & $4.25 \%$ \\
\hline 3.1.3 Learning & 13 & $13.68 \%$ & $4.25 \%$ \\
\hline 3.1.4 Tourism & 3 & $3.16 \%$ & $0.98 \%$ \\
\hline 3.1.5 Traffic & 3 & $3.16 \%$ & $0.98 \%$ \\
\hline 3.1.6 Others & $9<3$ & $9.48 \%$ & $2.94 \%$ \\
\hline 3.2 M-commerce & 10 & $10.53 \%$ & $3.27 \%$ \\
\hline 3.3 Information system & 12 & $12.63 \%$ & $3.93 \%$ \\
\hline 3.4 Communication system & 9 & $9.47 \%$ & $2.94 \%$ \\
\hline $3.5 \mathrm{Web}$-service & 11 & $11.58 \%$ & $3.59 \%$ \\
\hline 4 User infrastructure laver & 22 & $100 \%$ & $7.19 \%$ \\
\hline 4.1 User interface & 17 & $77.27 \%$ & $5.56 \%$ \\
\hline 4.2 Usability & 5 & $22.73 \%$ & $1.63 \%$ \\
\hline Total & 306 & & $100 \%$ \\
\hline
\end{tabular}

\section{Discussion, Implieation, and Conclusion}

Context-aware application has attracted the attention of both business and academics. This paper identifies 306 articles on context-aware application published between 2005 and 2014. Although this review does not claim to be exhaustive, it does provide a reasonable amount of insight into the state of the art in context-aware application research. We are confident that as context-aware application become increasingly pervasive, research in context-aware application will be more important internationally. The results presented in this paper have several important implications.

The concept and research layer has the highest percentage of context-aware articles (96 articles, $31.37 \%$ ). This layer can be divided into 6 subjects. They are context (26 articles, $8.49 \%$ ), framework (20articles, 6.54\%), context data management (16articles, 5.23\%), evaluation (10 articles, 3.27\%), privacy and security (15 articles, $4.90 \%)$ and overview (9 articles, 2.94\%). The concept of context is always one of the most debatable and controversial arguments that academia has not reach a consensus yet, especially the concept of organization context. Context data management has become one of the obstacles of the context-aware application. Erik et al introduced the concept of Contextualized Attention Metadata (CAM) to describe context [34]. However, CAM is 
restricted to small-scale data. For the forthcoming big data, existing technology seem incapable of action. Evaluation has been one of the hotspot of the study in context-aware application fields and plenty of typical models were generated such as Balanced Score Card (BSC), IS Success Model and so on. The issues of privacy and security have been plaguing the development of personalized service system and context-aware application [35]. Besides, it will result in violations of privacy and serious social problems, even directly affects the stability of society.

Computing layer (93 articles, 30.39\%) is the most critical layer of system implementation and operation. Scholars/researchers spent much more time in studying context modeling (29 articles, 9.48\%), contextual user preference elicitation (27 articles, $8.82 \%)$ and contextual recommendation generation (22 articles, $7.19 \%)$ rather than context identification and acquisition (15 articles, $4.90 \%)$ in this layer. Direct context are easily accessible but it proved difficult to extract meaningful context in the process of context identification and acquisition. Therefore, the ways of reasoning and implicit acquisition are generally adopted to obtain context information. Yap et al. presented the SVM method to dynamically identify the optimum context and further proposed iferation and filtering techniques based on Bayesian Network to remove the context parameters which have no influence on users' preferences [12]. Context modeling is /egarded as the most important part to mining the relationship among the user, context and item. Nevertheless, existing technologies about context modeling are complex, and each one has its advantages and disadvantages. It is absolutely vital to choose the appropriate modeling technique. Adomavicius et al suggested that a combined context recommendation technology (like multistage combination and linear combination of prediction model, the combined methods based on the machine learning technologies of boosting, bagging and stacking) should be designed to improve the accuracy, novelty, instantaneity, diversity and robustnes of recommendation [14]. The contextual preference elicitation technologies are also to numerous to mention. Table 2 has shown the comparison of different preference elicitat on technologies. Once the users' context changes, the users 'preference are also changes, namely preference evolution. However, these technologies cannot solve this issae effectively.

There are 95 artioles in the application layer, which account for $31.05 \%$ of the reviewed articles. This layer mainty includes 6 subjects: smart life (52 papers, 17.32\%), M-commerce (10 papers, 3.27\%), information system (12 papers, 3.93\%), communication system (9 papers, $2.94 \%$ ) and web service (11 papers, 3.95\%). Smart life can be also divided into 6 specific topies: home (12 papers, 3.92\%), health (13 papers, 4.25\%), learning (13 papers, $4.25 \%$ ), tourism (3 papers, 0.98\%), traffic (3 papers, $0.98 \%$ ) and others (9 papers, $2.94 \%$ ).All of these indicate that the context-aware applications have penetrated into every corner of our lives. We think that context-aware applications will have tremendous potential in the future. However, the scope of applications or services in most articles is limited to small regions: home, school, hospital and so on. In addition, context-aware applications have a long way to go before it comes in market cosmically as these applications are lack of strategic alternatives and business models for gaining the eyenue.

The user infrastructure layer (22 articles, $7.19 \%$ ) is the nearest layer to the user, which mainly includes two subjects: user interface (17 articles, $5.56 \%)$ and usability (5 articles, $1.63 \%)$. As main terminals of the context-aware applications, mobile devices have its inherent defaults, such as difficulty in input and display and poor data processing ability [36]. How to provide personalized information and services in such devices have plagued researchers and experts. However, the papers about this aspect are still rare. Scholars should strengthen the research in this respect. In conclusion for the above implications, we would like to offer the following suggestions for further research in context-aware application. 
(1)Future research should pay more attention to strategic alternatives and business models for gaining the revenue by using context-aware systems. As previously mentioned, many researches have focused on the context-aware theory, technology and application. Studies on strategic alternatives and business models for gaining the revenue by using context-aware systems are very few. Bessai et al proposed a context-aware business process approach to evaluate and enhance business process models for a context using work-flow patterns [37]. Existing literature mainly focused on the factors that explain failing business models rather than providing practical design issues to improve business model viability [38] Context-aware application would not be widely adopted without driving by the commercial interests under the market economy condition. In addition, it is urgent to provide better service to users and develop technologies integration, which is based on a good business model. We believe that context-aware application will be commercialized massively in the future.

(2)Future research should pay more attention to high quality system solutions and industry ecosystem on smart home. Current research mainly relate to involve single application, how to join these applications into an ecosystem at the same intelligence environment is still to be a difficult technical problem. For example, it plagued by fragmented and lack of high quality system in the field of smart home, besides we have a lot of brands of smart home device, but they hardly conpatible as its technical standards disunion. Above all, Due to the lack of support of the ecosystem, the smart home is difficult to form a non-boundary system solutions at present.

(3)Future research should pay more attention to the context data processing technology. Data in our world has been explocing, multimedia and individuals with smartphones and on social network sites will continue to fuel exponential growth [39] However, it is difficult to find valuable data as the datacensity is too low. In other words, the data processing has become unusually onerous, and context data processing is certainly no exception. In a situation like this, it becomes very troublesome to analysis and excavate user's preference and to explore the relation among the user, item and its context. It is urgent to make a study of context data processing technology emphatically and we believe that there ISgoing to be a flood of technologies in this area.

(4)Future research should pay more attention to evolution of contextual user preference. Contextual user preferende is not fixed. On the contrary, it would be changed by internal and external factors such as age, experience, circumstances and people around them [40].For instance, when we are at the clothing store, choice preference of people on clothing will change along with age, size, status and so on. We need to collect existing context so as to extract hey preference while the original preference changed. Otherwise, the accuracy rate of the recommended may drop significantly and inaccuracy recommendations may frustrate users. Therefore, it is extraordinary important to intensify the analysis and study of the evolution of contextual user preference.

(5)Future research should pay more attention to the context-aware application evaluation and intelligent information processing among mobile devices. The recommending efficiency of context-aware application is not only related to context-aware technologies but also to the setting of evaluation indexes. Existing research only pay attention to the accuracy, but ignore the real-time, novelty and robustness of recommendation [14].In addition, massive mobile devices with computing and storage capacity emerge in an endless stream. Since a large number of restrictions of these mobile devices in screen size, computing power, storage capacity and connection speed, therefore, a profound reform is definitely necessary for the ways of information storage, organization, retrieval and dissemination in mobile interfaces [41]. We look forward to seeing contributions and breakthroughs in this field in the near future.

(6)Future research should pay more attention to privacy and security of context-aware applications. Problems on privacy and security have plagued personalized recommender system for a long time. Especially smart home, it will cause irreparable damage once the 
information leakage while it records our daily lives [42]. The privacy and security of context-aware applications are quite complicated and difficult to solve. But solutions about this are rare. Scholars should strengthen the research in this respect. Certainly, there are still some deficiencies in this paper. Regardless of all the efforts we have made to search context-aware relevant papers from multiple sources, the limitations of descriptors we have chosen may still lead to a lack of some correlative articles in this review.

\section{Acknowledgement}

This work is supported by the Natural Science Foundation of China (No: 71373192) and the MOE Project of Key Research Institute of Humanities and Social Science in Chinese Universities (NO: 14JJD870002).

\section{References}

[1] Zhu, F., Mutka, M. W., and Ni, L. M, "Service discovery in pervasive computing enviromments", IEEE Pervasive Computing., Vol.4, No.4, (2005), pp.81-90.

[2] Bolchini, C., Schreiber, F. A. and Tanca, L, "A methodology for a very small database design", Information Systems., Vol. 32, No.1, (2007), pp.61-82.

[3] Schilit, B. and Theimer, M, "Disseminating active map information to mobile hosts" IEEE Network., Vol. 8, No. 5, (1994), pp.22-32.

[4] Hull, R., Neaves, P. and Bedford-Roberts, J, "Towards Situated Computing", In Proceedings of the 1st IEEE International Symposium on Wearable Computers, IEEE Computer Society, Washington, DC, USA, (1997), pp.146-153.

[5] Dey, A.K. and Abowd, G.D, "Towards a better understanding of context and context-awareness", First International Symposium, HUC'99 Karlsruhe, Germany, (1999), September 27-29.

[6] Ricci F, "Mobile recommender systems", Jound of Information Technology and Tourism. Vol.12, No.3, (2011), pp.205-231.

[7] Woerndl W, Brocco M and Eigner R "Cohtext-Aware recommender systems in mobile scenarios", International Journal of Information Technology and Web Engineering., Vol.4, No.1, (2009), pp.67-85.

[8] Shin D, Lee JW, Yeon J and Lee SG, Context-Aware recommendation by aggregating user context", IEEE Conference on Commerce and Enterprise Computing (CEC'09), Vienna, Austria, (2009), July 20-23.

[9] White R, Bailey P, Chen LW, "Predicting user interests from contextual information". Proc. of the SIGIR, Boston, America, (2009), July 19-23.

[10] Hong JY, Suh EH, KIn SJ, "Context-Aware systems: A literature review and classification", Expert Systems with Applications, Vol. 36, No.4, (2009), pp.8509-8522.

[11] Adomavicius G, Tuzhilin A., "Context-Aware recommender systems", Recommender Systems Handbook, Springer-Verlag, Berlin, (2011),pp.217-253.

[12] Yap GE, Tan AH, Pang HH., "Discovering and exploiting causal dependencies for robust mobile context-aware recommender", IEEE Transactions on Knowledge and Data Engineering., Vol.19, No.7, (2007), pp.977-992

[13] Su JH, Yeh HH, Yu PS, and Tseng VS., "Music recommendation using content and context information mining", IEEE Intelligent Systems., Vol.25, No.1, (2010), pp.16-26.

[14] Adomavicius G Sankaranarayanan R, Sen S, and Tuzhilin A., "Incorporating contextual information in recommender systems using a multidimensional approach", ACM Transactions on Information Systems., Vol 23, No.1, (2005), pp.103-145.

[15] Kahng M, Lee SK, Lee SG., "Ranking in context-aware recommender systems", Proceedings of the 20 th international conference companion on World Wide Web (WWW '11), Hyderabad, India,(2011),March 28-April 01.

[16] Rendle S, Gantner Z, Freudenthaler C, Schmidt-Thieme L., "Fast context-aware recommendations with factorization machines". The 34th Annual ACM SIGIR Conference, Beijing, China, (2011), July 24-28.

[17] Herlocker JL, Konstan JA, Terveen LG, Riedl JT., "Evaluating collaborative filtering recommender systems", ACM Transactions on Information Systems. Vol. 22 No.1, (2004), pp.5-53.

[18] Bora Dreamer, José Luis García-Lapresta, David Pérez-Román, M. Remzi Sanver, "Measuring consensus in a preference-approval context", Information Fusion, Volume 17, (2014), pp14-21

[19] Baek, S. H., Lee, H. J., Lim, S. Y., and Huh, J. D., "Managing mechanism for service compatibility and interaction issues in context-aware ubiquitous home", IEEE Transactions on Consumer Electronics, Vol. 51, No. 2, (2005), pp.524-528.

[20] Bellotti, F., Berta, R., De Gloria, A., and Margarone, M., "Implementing tour guides for travelers", Human Factors and Ergonomics in Manufacturing, Vol. 15, No.4, (2005), pp.461-476. 
[21] Jun, S., Kai S. K, and Marshall, S. P, "Critical success factors for context-aware mobile communication systems", Int. J. of Mobile Communications, Vol.7, No.3, (2009), pp. 290-307

[22] Lorna, U. and Petri, H., "Designing mobile interfaces using activity theory", International Journal of Mobile Communications, Vol.6, No.5, (2008), pp.616-632.

[23] Rahman, M.A., "Sense Face: Towards a context-aware social network framework", PhD Thesis, University of Ottawa, Canada (2008).

[24] Lagvankar, T. V. "Collaborative data gathering using context-aware mobile devices", Master"s Thesis, University of Maryland, Baltimore County, USA (2010).

[25] Rattenbury, T. L. "An activity based approach to context-aware computing", $\mathrm{PhD}$ Thesis University of California, Berkeley, USA (2008).

[26] Phithakkitnukoon, S. "Inferring social and internal context using a mobile phone", $\mathrm{PhD}$ Thesis, University of North Texas, USA, (2009).

[27] Ergut, S., "Context-aware computing for wireless networks", PhD Thesis, University of California, San Diego, USA (2010).

[28] Mei, L., "Cognitive context elicitation and modeling", PhD Thesis, University of Toronto, (2011).

[29] Ricardo, C., and Markus, E. "Context Management for Distributed and Dynamic Context-Aware Computing", Springer, London (2012).

[30] Jagtap, P., "Privacy preservation in context-aware systems", Master's Thesis, University of Maryland, Baltimore County. USA (2011).

[31] Spargo, J. N., "Privacy for location-based services with smartphones", Master's Thesis, The University of Texas at Arlington. USA (2011).

[32] Hassan, T., "A mobile context-aware behavior modification systen for healthy lifestyle management", $\mathrm{PhD}$ Thesis, the Claremont Graduate University, USA (2008).

[33] Crowley J L, Coutaz J. "An Ecological View of Smart Home Technologies “Ambient Intelligence. Springer International Publishing, (2015), 1-16.

[34] Erik Duval, Martin Wolpers, Jehad Najjar. "Collecting, managing and exploiting of rich usage information", Conference on Information and Knowledge Management (CIKM '06), Arlington, America, (2006), November 05-11.

[35] Wilson C, Hargreaves T, Hauxwell-Baldwin R "Smart homes and their users: a systematic analysis and key challenges", Personal and Ubiquitous Computing, Vol. 19 No.2, (2015), 463-476.

[36] Morris, R.P. and Tomlinson, J.J. "A mobile cevice user inteface with a simple, classic design", IEEE Transactions on Consumer Electronics, Vol.54 No.3, (2008), pp.1252-1258.

[37] K. Bessai, B. Claudepierre, O. Saidani, and S. Nurcan, "Context-aware business process evaluation and redesign”, In: Proc. of the 9th Workshop on Business Process Modeling, Development and Support, Montpellier, France,(2008), June 16-17 .

[38] Mark de R., Timber H "Designing viable business models for context-aware mobile services", Telematics and Informatic. Yol. 26 No.3, (2009), pp.240-248,

[39] James M., Michael C., Brad B., "Big data: The next frontier for innovation, competition, and productivity", McKmsey Global Institute, Chicago. IL, USA, (2012).

[40] Chang, C.K.; Hsinyi Jiang; Ua Ming; Oyama, K., "Situ: A Situation-Theoretic Approach to Context-Aware Service Evolution, IEEE Transactions on Services Computing., Vol.2, No.3, (2009), pp. 261-275.

[41] Lorna, U. and Petri, H. Designing mobile interfaces using activity theory", International Journal of Mobile Communication Vol.6 No.5, (2008), pp.616-632.

[42] Kirkham, T., Armstrong, D., Djemame, K., \& Jiang, M. "Risk driven Smart Home resource management using cloud services". Future Generation Computer Systems, Vol.38, (2014), 13-22.

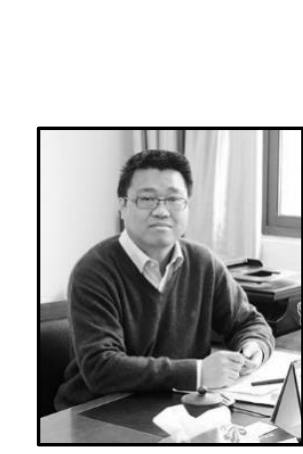

\section{Authors}

Liyi Zhang, He is a Professor of department of Information \& E-commerce in School of Information Management, Wuhan University. His research interests include information system, e-commerce and information Retrieval. Professor Zhang has published five books, over 40 professional papers in refereed journals and national and international conference proceedings. 


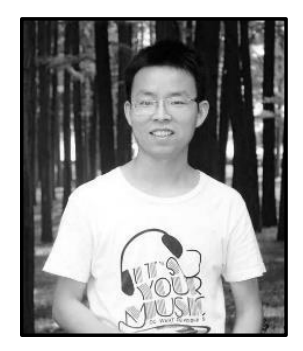

Cong Yin, $\mathrm{He}$ is a $\mathrm{Ph} . \mathrm{D}$. candidate in management science and engineering at the School of Information Management, Wuhan University. His research interests include E-commerce, information system.

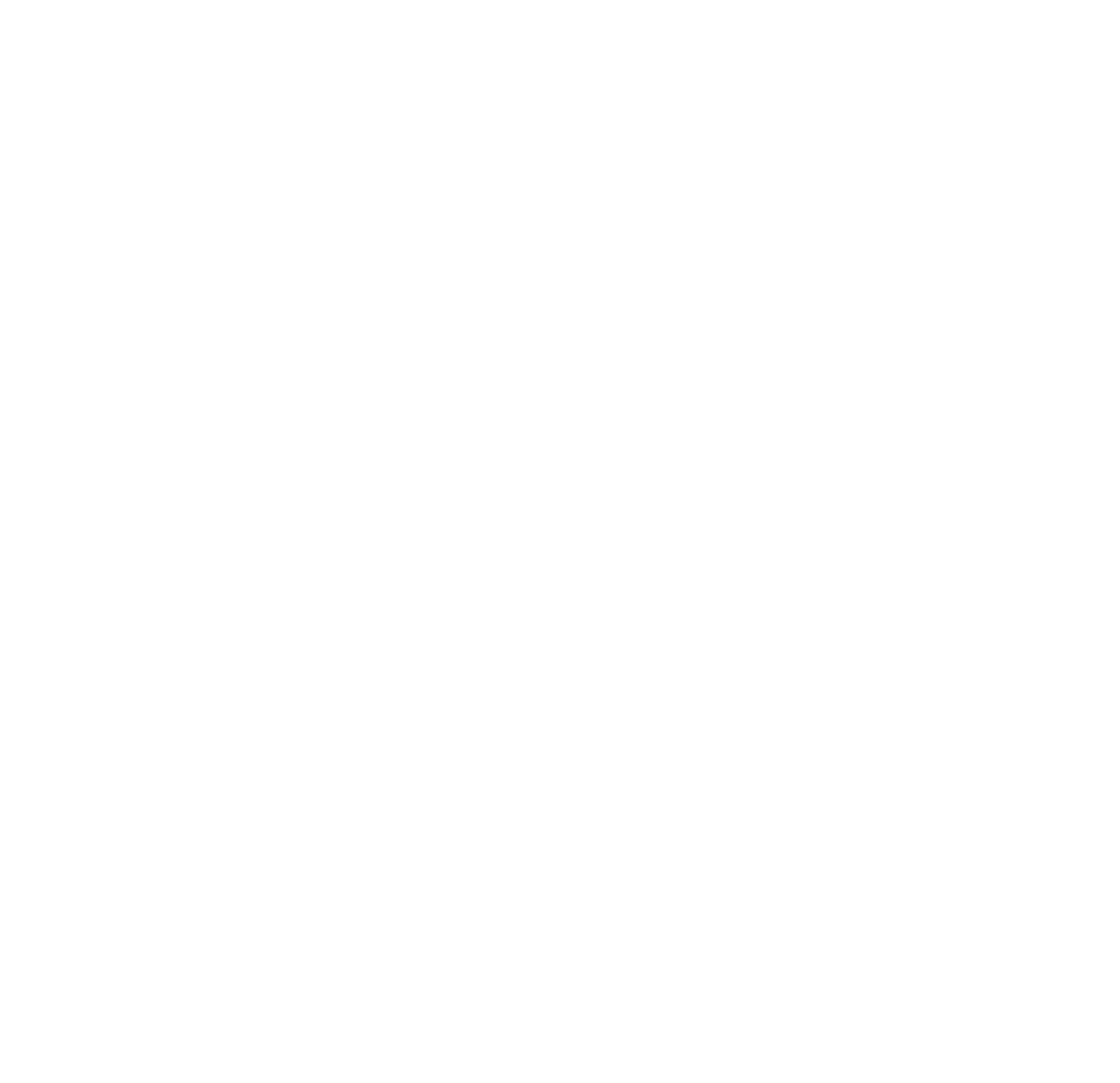


International Journal of Smart Home

Vol.10, No.10 (2016)

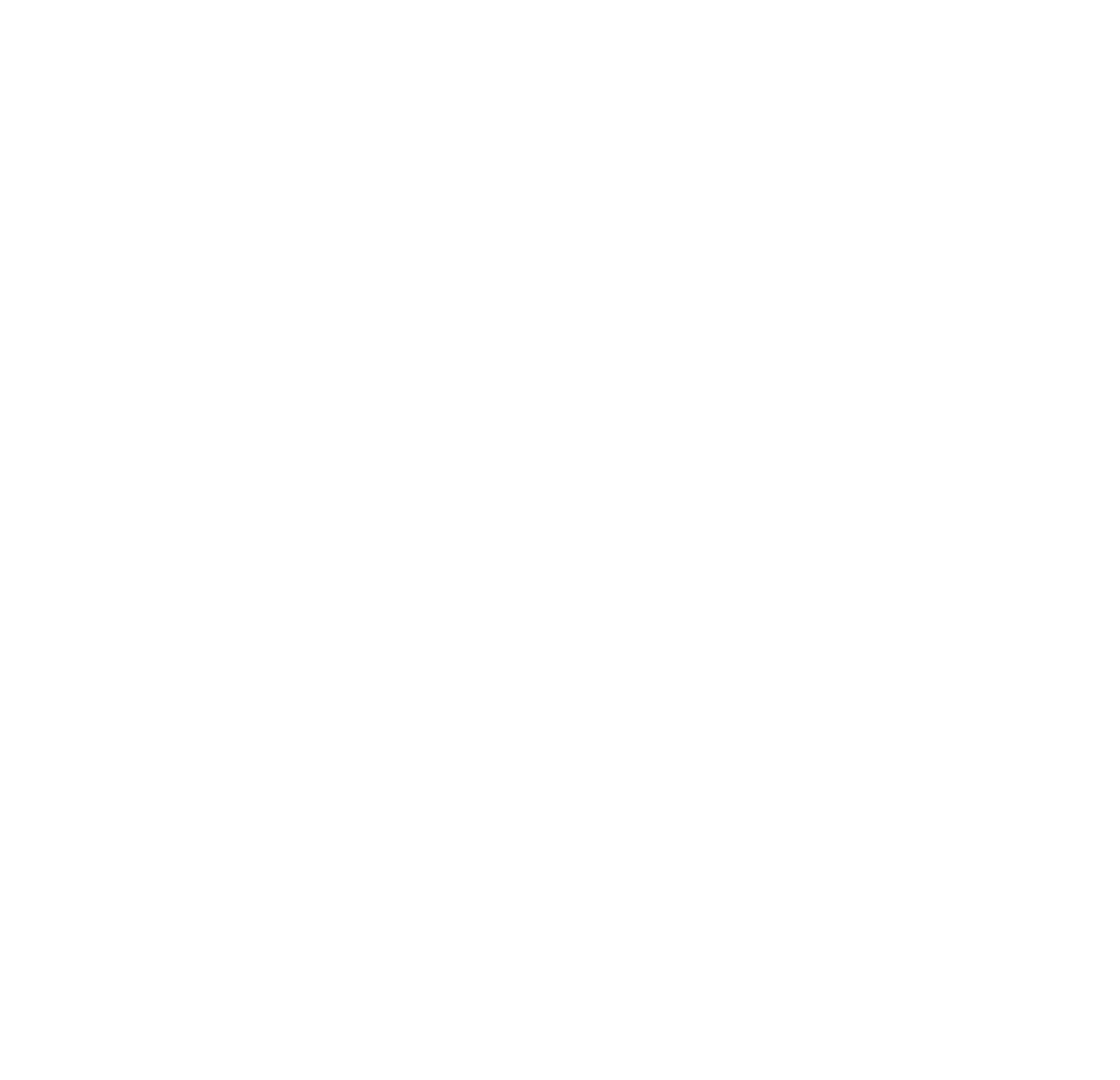

